\title{
ANALISIS LAJU SEDIMENTASI DI PERAIRAN PULAU BUNGKUTOKO SULAWESI TENGGARA
}

\section{Analysis of Sedimentation Rates in Bungkutoko Island Southeast Sulawaesi}

\author{
La Ode Ahmad Jawahir ${ }^{1}$, La Ode Alirman Afu ${ }^{1}, \operatorname{Ira}^{1}$ \\ ${ }^{1}$ Mahasiswa Jurusan Ilmu Kelautan, \\ Fakultas Perikanan dan Ilmu Kelautan, Universitas Halu Oleo. \\ Jl. H.E.A Mokodompit Kampus Hijau Bumi Tridharma Anduonohu Kendari 93232, Telp/Fax: (0401) 3193782 \\ ${ }^{2}$ Surel : alirmanotsudari@yahoo.co.id \\ ${ }^{2}$ Surel : bahari_00@yahoo.co.id
}

\begin{abstract}
Abstrak
Tujuan dari penelitian ini adalah untuk mengetahui laju sedimentasi di Perairan Pulau Bungkutoko. Pengambilan data penelitian ini dilaksanakan selama 3 bulan yaitu pada bulan Agustus - Oktober 2018. Data sedimen diperoleh menggunakan sediment trap yang dipasang pada 5 stasiun dengan 2 kali pengambilan sampel selama 6 minggu. Laju sedimentasi dianalisis menggunakan formula APHA (1976). Hasil penelitian menunjukkan bahwa rata-rata laju sedimentasi tertinggi terdapat pada stasiun 4 yakni sebesar $2.608,84 \mathrm{~g} / \mathrm{m}^{3} /$ hari. Sedangkan nilai rata-rata laju sedimentasi terendah berada pada stasiun 2 yakni sebesar $749,77 \mathrm{~g} / \mathrm{m}^{3} /$ hari. Laju sedimentasi tersebut dipengaruhi oleh arus dan gelombang.
\end{abstract}

Kata kunci : Laju Sedimentasi. Sedimentasi, Pulau Bungkutoko, Sediment Trap

\begin{abstract}
This study was carried out to analize sedimentation rate in Bungkutoko Island. It was conducted from August to October 2018. Sediment material was obtained using sediment trap installed at 5 stations with 2 times sampling for 6 weeks. Sedimentation rate was analysed by APHA (1976) formula. Results showed that the highest sedimentation rate was $2.608,84 \mathrm{~g} / \mathrm{m}^{3} /$ day which dominantly occurred in station 4 while the lowest rate recorded was $749,77 \mathrm{~g} / \mathrm{m}^{3} /$ day occurred in station 2 . The sedimentation rate was relatively influenced by water current and wave.
\end{abstract}

Kaeyword : Bungkutoko Island, Sedimentation, Sedimentation Rate. Sediment Trap

\section{Pendahuluan}

Sedimentasi adalah proses pengendapan material yang terangkut oleh aliran dari bagian hulu akibat dari erosi. Sungai-sungai membawa sedimen dalam setiap alirannya. Laju sedimentasi adalah banyaknya massa sedimen yang terangkut melalui suatu satuan luas dalam setiap satuan waktu (Alimudin, 2012). Laju sedimentasi di suatu perairan dapat berbeda karena disebabkan oleh beberapa faktor seperti kecepatan arus dan komposisi sedimen dasarnya.

Nursanti $d k k$. (2013), menemukan nilai laju sedimentasi yang berbeda antara perairan Teluk Awur dengan perairan Bandengan. Penelitian lainnya yang pernah dilakukan berkaitan dengan analisis laju sedimentasi yaitu Trianto dkk. (2016), tentang analisis laju sedimentasi terhadap ketersediaan air irigasi dan arahan konservasi pada bendung lakitan. Arifiyana $d k k$. (2015), juga pernah melakukan penelitian tentang Pengaruh Longshore Current terhadap Laju
Sedimentasi di Area Jetty Prophyline dan Jetty Cargo PT. Pertamina RU VI Balongan Indramayu.

Pulau Bungkutoko merupakan pulau yang terletak pada bagian depan Teluk Kendari. Kondisi Perairan Pulau Bungkutoko telah mengalami banyak perubahan yang diakibatkan dengan adanya pembangunan jembatan serta kegiatan reklamasi. Sarbidi (2005), mengatakan bahwa pembangunan terus menerus di wilayah pesisir menimbulkan banyak permasalahan. Hal tersebut diduga dapat menyebabkan terjadinya degradasi dan permasalahan, salah satunya berupa sedimentasi di dasar perairan (Wisha dkk., 2015). Sejauh ini informasi tentang laju sedimentasi di perairan Pulau Bungkutoko masih sangat kurang sehingga perlu dilakukan penelitian di lokasi tersebut. Penelitian ini bertujuan untuk mengetahui laju sedimentasi di perairan Pulau Bungkutoko Sulawesi Tenggara. 


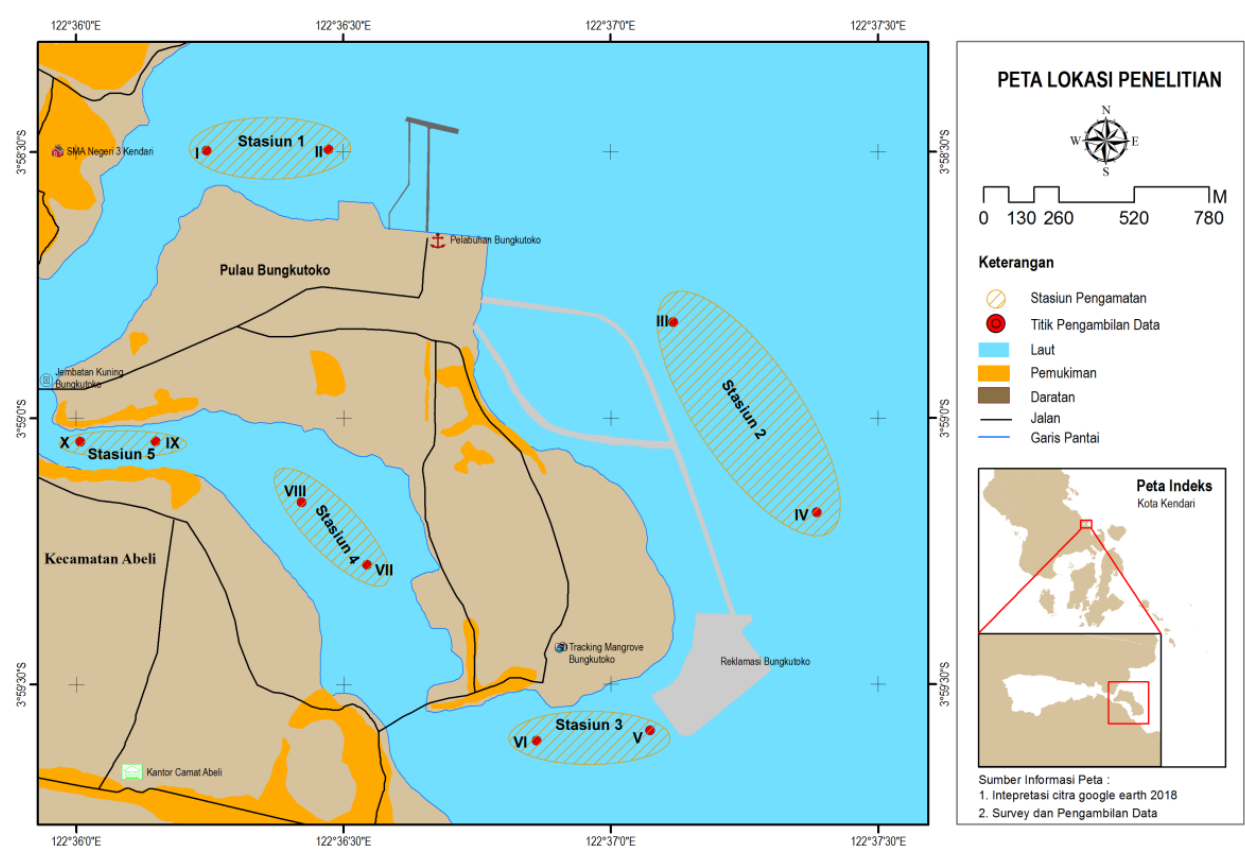

Gambar 1. Lokasi penelitian

\section{Bahan dan Metode}

Pengambilan data penelitian ini dilaksanakan selama 3 bulan yaitu pada bulan Agustus-Oktober 2018, bertempat di perairan Pulau Bungkutoko (Gambar 1). Analisis sampel sedimen dilakukan di Laboratorium Uji Materia Jurusan Teknik Sipil, Fakultas Teknik, Universitas Halu Oleo, Kota Kendari, Provinsi Sulawesi Tenggara.

Penentuan stasiun pengambilan sampel dilakukan berdasarkan kondisi lingkungan dan juga letaknya dimana lokasi tersebut terindikasi terjadinya sedimentasi. Pengambilan sampel sedimen dilakukan dengan menggunakan alat sediment trap. Sediment trap terbuat dari pipa paralon yang berdiameter $10 \mathrm{~cm}(\mathrm{r}=5 \mathrm{~cm})$ dan panjang pipa $30 \mathrm{~cm}$ (Nursanti $d k k$., 2013).

Pengambilan sediment trap pada masing-masing stasiun dilakukan sebanyak 2 kali dengan selang waktu 6 minggu. Pengeringan sampel sadimen yang terperangkap pada sediment trap menggunakan oven. Setelah kering sedimen disaring menggunakan saringan sedimen untuk memisahkan batu ataupun sejenisnya dari sedimen. Bila sudah didapat sedimen yang kering, kemudian sedimen ditimbang menggunakan timbangan digital untuk mengetahui berat sedimen tersebut. Pengukuran parameter penunjang yaitu arus, gelobang dan kedalaman juga dilakukan dengan selang waktu 6 minggu sebanyak 3 kali pengulangan terhitung sejak pemasangan sediment trap.

Laju sedimentasi merupakan banyaknya atau berat sedimen yang mengendap persatuan volume dan persatuan waktu misalnya satuan yang digunakan adalah g/m3/hari. Perhitungan laju sedimentasi (Ls) sebagai berikut :

$\mathrm{Ls}=\mathrm{Bs} / \mathrm{Vst} / \mathrm{T} \quad \mathrm{Vst}=\pi \mathrm{r}^{2} \mathrm{t}$

Keterangan :

Ls = Laju Sedimentasi $\left(\mathrm{g} / \mathrm{m}^{3} / \mathrm{hari}\right)$

Vst $=$ Volume Tabung

Bs $=$ Berat Kering Sedimen (gr)

$\mathrm{T}=$ Lama Pemasangan (hari)

English (1994), menyatakan bahwa kecepatan arus diukur menggunakan layangan arus serta waktu tempuh layangan arus tersebut dihitung menggunakan stopwatch. Analisis kecepatan arus dilakuakan dengan menggunakan rumus $\mathrm{V}=\mathrm{s} / \mathrm{t}$

Keterangan :

$\mathrm{V}=$ kecepatan arus $(\mathrm{m} / \mathrm{s})$

$\mathrm{s}=$ panjang lintasan layangan arus $(\mathrm{m})$

$\mathrm{t}=$ waktu tempuh layangan arua $(\mathrm{s})$

Sedangkan untuk mengukur tinggi gelombang menggunakan rumus sebagai berikit:

$h=\frac{a+b}{2}$

keterangan 
$\mathrm{h}=$ Tinggi gelombang $(\mathrm{cm})$

$\mathrm{a}=$ puncak gelombang $(\mathrm{cm})$

$\mathrm{b}=$ lembah gelombang $(\mathrm{cm})$

\section{Hasil dan Pembahasan}

Laju sedimentasi di suatu perairan dapat berbeda karena disebabkan oleh beberapa faktor seperti kecepatan arus dan komposisi sedimen dasarnya. Hasil penelitian seperti yang dilihat pada Tabel 1 menunjukan bahwa laju sedimentasi pada stasiun 1 diperoleh nilai rata-rata sebesar 2470,43 $\mathrm{g} / \mathrm{m} 3 /$ hari, $\quad$ stasiun 2 sebesar 749,77 g/m3/hari, stasiun 3 sebesar 813,26 $\mathrm{g} / \mathrm{m} 3 /$ hari, stasiun 4 sebesar 2608,84 $\mathrm{g} / \mathrm{m} 3 /$ hari, dan stasiun 5 sebesar 917,30 $\mathrm{g} / \mathrm{m} 3 /$ hari. Besarnya laju sedimentasi pada stasiun 4 disebabkan oleh kondisi fisika perairan yang memiliki arus yang cukup tinggi yaitu sebesar $0,43 \mathrm{~m} / \mathrm{s}$ dan kodisi perairannya tenang dengan nilai gelombang sebesar $0 \mathrm{~cm}$ (Tabel 2). Selain itu, lokasi tersebut juga berada pada muara dan hampir tidak pernah dilewati oleh kapal. Hastari dkk., (2016) menyatakan bahwa kondisi perairan yang cukup tenang dan tidak terlewati oleh kapal umumnya memiliki laju sedimentasi yang tinggi. Hal ini disebabkan oleh material sedimen yang terbawa arus akan langsung terendapkan.

Berdasarkan Tabel 1, dapat dilihat bahwa nilai laju sedimentasi terendah diketahui terdapat pada stasiun 2 yaitu sebesar $749,77 \mathrm{~g} / \mathrm{m}^{3} /$ hari. Rendahnya nilai laju sedimentasi tersebut dapat disebabkan oleh kondisi perairan yang berada tepat berhadapan langsung dengan laut bebas, merupakan jalur pelayaran, terdapat ekosistem lamun dan terdapat aktivitas reklamasi. Hastari dkk., (2016) menyatakan bahwa pada daerah alur pelayaran kapal, partikel sedimen di dasar perairan akan mengalami pengadukkan yang dapat mengakibatkan matrial sedimen terobangambing akibat dari gelombang yang terjadi akibat dari aktifitas pelayaran. Selain itu, rendahnya nilai laju sedimentasi tersebut juga dapat dipengaruhi oleh kondisi fisika perairan seperti arus, gelombang dan kedalaman.

Tabel 1. Hasil Rata-Rata Laju Sedimentasi Setiap Stasiun/Titik

\begin{tabular}{|c|c|c|c|c|c|c|c|}
\hline \multirow{3}{*}{ Stasiun } & \multirow{3}{*}{ Titik } & \multicolumn{5}{|c|}{ Laju sedimentasi (g/m3/hari) } & \multirow{3}{*}{$\begin{array}{c}\text { Rata - rata per } \\
\text { stasiun } \\
\text { (g/m3/hari) }\end{array}$} \\
\hline & & \multirow{2}{*}{ Suspensi } & \multicolumn{4}{|c|}{ Sedimen dasar } & \\
\hline & & & Utara & Selatan & Timur & Barat & \\
\hline \multirow{2}{*}{1} & I & 645,03 & 2545,75 & 4992,42 & 1182,89 & 1337,58 & \multirow{2}{*}{2470,43} \\
\hline & II & 577,29 & 3704,38 & 830,05 & 5628,35 & 3260,54 & \\
\hline \multirow{2}{*}{2} & III & 665,25 & 887,68 & 772,42 & 569,20 & 776,46 & \multirow{2}{*}{749,77} \\
\hline & IV & 652,11 & 851,28 & 849,26 & 682,44 & 791,63 & \\
\hline \multirow{2}{*}{3} & $\mathrm{~V}$ & 703,67 & 1255,69 & 667,27 & 657,16 & 872,51 & \multirow{2}{*}{813,26} \\
\hline & VI & 726,92 & 1222,32 & 595,49 & 675,36 & 756,24 & \\
\hline \multirow[t]{2}{*}{4} & VII & 1261,75 & 4688,10 & 1569,10 & 843,19 & 8302,50 & \multirow{2}{*}{2608,84} \\
\hline & VIII & 1073,70 & 1645,94 & 1383,08 & 754,22 & 4566,78 & \\
\hline \multirow[t]{2}{*}{5} & IX & 719,85 & 639,98 & 650,09 & 981,70 & 1245,58 & \multirow[t]{2}{*}{917,30} \\
\hline & $X$ & 919,02 & 1009,00 & 887,68 & 953,39 & 1166,72 & \\
\hline
\end{tabular}

Tabel 2. Faktor Oseanografi Fisika

\begin{tabular}{|c|c|c|c|c|c|c|}
\hline \multirow{2}{*}{ No } & \multirow{2}{*}{$\begin{array}{c}\text { Parameter } \\
\text { Oseanografi fisika }\end{array}$} & \multicolumn{5}{|c|}{ Stasiun } \\
\hline & & 1 & 2 & 3 & 4 & 5 \\
\hline 1 & Arus (m/s) & 0,43 & 0,53 & 0,42 & 0,43 & 0,21 \\
\hline 2 & Gelombang $(\mathrm{cm})$ & 7,6 & 6,62 & 5,34 & 0 & 5,08 \\
\hline
\end{tabular}




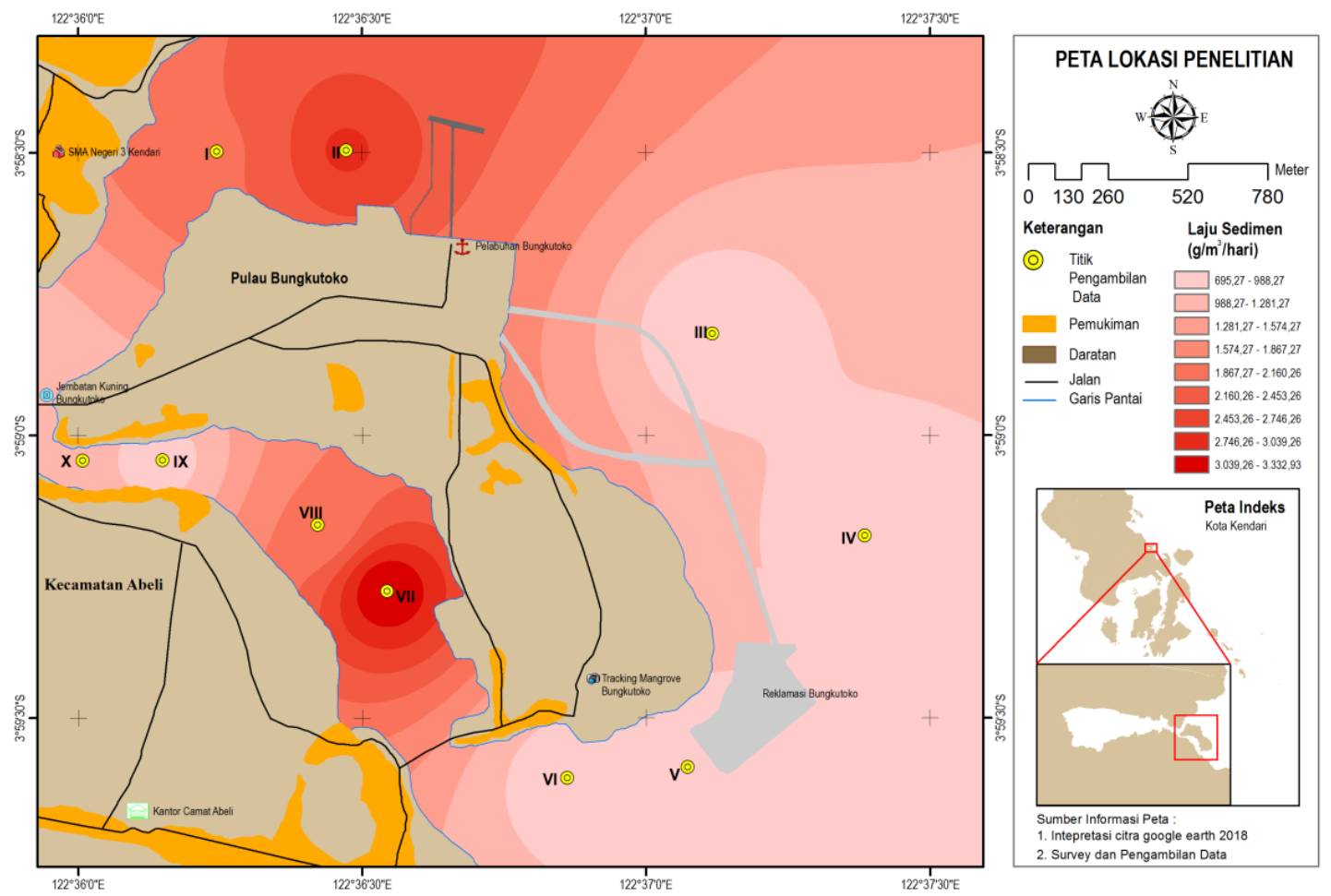

Gambar 2. Peta laju sedimentasi

Sebagai pembanding dalam penelitian yang lain, rata-rata laju sedimentasi di sekitar mulut Teluk Kendari berkisar antara 0,01$0,05 \mathrm{mg} / \mathrm{cm}^{2} /$ hari (Subhan dan Afu, 2017). Diantara 5 titik stasiun penelitian, nilai tertinggi untuk kecepatan arus, gelombang dan kedalaman terdapat pada stasiun 2 sehingga tingginya kecepatan arus dan gelombang tersebut menyebabkan sulitnya sedimen untuk mengendap. Hal ini didukung oleh pernyataan Siswanto (2004) bahwa erosi, pengangkutan dan sedimentasi di perairan terjadi akibat proses mekanik yang dipengaruhi oleh beberapa faktor antara lain; kecepatan arus, ukuran partikel, kedalaman perairan, jumlah partikel, berat spesifik dari partikel, dan topografi (slope dasar perairan).

Faktor oseanografi fisika yang dapat mempengaruhi laju sedimentasi adalah kecepatan arus, gelombang dan kedalaman. Berdasarkan penelitian yang telah dilakukan, diperoleh nilai kecepatan arus, gelombang dan kedalaman di Perairan Pulau Bungkutoko.

\section{Simpulan}

Berdasarkan penelitian yang telah dilakukan, dapat disimpulkan bahwa laju sedimentasi tertinggi yaitu berada di bagian stasiun 4 sebesar $782,65 \mathrm{~g} / \mathrm{m}^{3} /$ hari. Sedangkan terendah di bagian luar teluk dan berhadapan dengan laut bebas, pada stasiun 2 sebesar 224,93 g/ $/ \mathrm{m}^{3} /$ hari. Faktor oseanografi fisika seperti arus, gelombang dan kedalaman adalah yang paling memberi pengaruh terhadap laju sedimentasi. Selain itu, aktivitas manusia juga memberi dampak terhadap laju sedimentasi di perairan Bungkutoko.

\section{Ucapan Terimakasih}

Ucapan terimakasih penulis sampaikan kepada tim Pulau Bungkutoko yang telah membantu dalam pengambilan sampel: Syahril syam, LaOde Anshari, La Ode Ahmad Safii, Fadly Alqadri, Aan Pratama, Siti Hasma, Sofyan Setiawan, Reny Windry Ayu L.P, Sartini dan Ria Amelia Safitri Walyanse.

\section{Daftar Pustaka}

Alimuddin, A. 2012. Pendugaan Sedimentasi pada Das Mamasa Di Kab. Mamasa Propinsi Sulawesi Barat. [Skripsi]. Fakultas Pertanian, Universitas Hasanuddin, Makassar. 62 Hal.

Arifiyana, A., Widada, S. dan Sugianto, D,N. 2015. Pengaruh Longshore Current 
terhadap Laju Sedimentasi di Area Jetty Prophyline dan Jetty Cargo PT. Pertamina RU VI Balongan Indramayu. Jurnal oseanografi. Vol. 4 (3) : 598-607.

Hastari, S. D., Rifai, A. dan Maslukah, L. 2016. Pemetaan Batimetri dan Laju Sedimentasi untuk Alur elayaran di Pelabuhan Perikanan Pantai (PPP) Tegalsari, Tegal. Jurnal Oseanografi. Vol. 5 (2) : 234-242.

Lanuru, M. dan Fitri, R. 2005. Sediment Deposition in A South Sulawesi Seagrass Bed. Universitas Hasanudin, Makassar.

Nursanti, Riniatsih, I. dan Satriadi, A. 2013. Studi Hubungan Kerapatan Vegetasi Lamun dengan Laju Sedimentasi di Perairan Teluk Awur dan Bandengan Jepara pada Periode Juni - Juli 2012. Journal of Marine Research. Vol. 2 (3) :25-34.

Rahman, B.M.K.2017 Laju Sedimentasi dan Perubahan Kedalaman di Kolom Pelabuhan Perikanan Nusantara Pelabuhanratu. Skripsi. Institut Pertanian Bogor : Bogor

Sarbidi. 2005. Pengaruh ROB Pada Pemukiman Pantai (Kasus Semarang). Makalah dan Presentasi Kerugian pada Bangunan dan Kawasan Akibat Kenaikan Muka Air Laut pada Kota Kota Pantai di Indonesia, Bandung.

Siswanto, AD. 2004. Kajian Laju Sedimentasi dan perubahan garis pantai di perairan Delta Bodri, Kabupaten Kendal. Skripsi. Ilmu Kelautan, FPIK-Undip.Semarang.

Subhan, Afu LOA. 2017. Pengaruh laju sedimentasi terhadap rekrutmen karang di Teluk Kendari, Provinsi Sulawesi Tenggara. Jurnal Manusia dan Lingkungan, 24(2): 73-80

Trianto, R., Andawayanti, U. dan Asmaranto, R. 2016. Analisis Laju Sedimentasi Terhadap Ketersediaan Air Irigasi dan Arahan Konservasi pada Bendung Lakitan. Jurnal Teknik Pengairan. Vol. 7 (1) : 95-106.

Wisha, U.J., Husrin, S., Prihantono, J. (2015). HIdrodinamika Perairan Teluk Banten pada Musim Peralihan (Agustus-September). J. Ilmu Kelautan 20(2): 101-112. 